\title{
Implementasi Sistem Informasi Geografis untuk Pemetaan Sebaran Jumlah Penduduk di Kota Cimahi
}

\author{
Dani Hamdani ${ }^{1}$, R.A.E. Virgana T Saptanji ${ }^{2}$ \\ ${ }^{1,2}$ Program Studi Sistem Informasi, Universitas Widyatama, Bandung, Indonesia \\ e-mail: ${ }^{1}$ dani.hamdani@widyatama.ac.id, ${ }^{2}$ rae.virgana@widyatama.ac.id
}

\begin{abstract}
Abstrak
RPJP Daerah Kota Cimahi 2005-2025 menyebutkan bahwa pertumbuhan penduduk dan persebaran-nya telah menjadi isu strategis dan perlu diatasi secara bertahap dan berkesinambungan, oleh karena itu monitoring sebaran kependudukan merupakan sesuatu yang harus dilakukan secara berkelanjutan. Metode pengembangan perangkat lunak yang digunakan adalah metode Rational Unified Process (RUP).RUP menggunakan konsep object-oriented, dengan aktifitas yang berfokus pada pengembangan model dengan menggunakan Unified Model Language (UML).Penelitian ini bertujuan untuk membangun sistem informasi geografis yang menampilkan pemetaan sebaran jumlah penduduk di Kota Cimahi. Data-data diperoleh dari publikasi Badan Pusat Statistik Kota Cimahi. Sistem ini dibangun menggunakan QGIS untuk membangun peta, postgreSQL untuk pengelolaan basis data dan bahasa pemrograman PHP untuk menampilkan peta ke halaman web. Kesimpulan akhir dari penelitian ini didapatkan bahwa sistem informasi geografis yang dibangun dapat menunjukkan informasi sebaran penduduk Kota Cimahi dengan baik sehingga pemerintah dapat menetapkan kebijakan yang lebih tepat.
\end{abstract}

\section{Kata kunci: Sistem Informasi Geografis, Sebaran penduduk, Kota Cimahi}

Abstract
The Cimahi Regional RPJP 2005-2025 states that population growth and its distribution have become strategic issues and need to be addressed in a gradual and continuous manner, therefore monitoring population distribution is something that must be carried out sustainably. The software development method used is the Rational Unified Process (RUP) method. RUP uses the object-oriented concept, with activities that focus on developing models using the Unified Model Language (UML). This research aims to build a geographic information system that displays a mapping of population distribution in Cimahi City. The data was obtained from the Cimahi City Central Statistics Agency publication. This system was built using QGIS to build maps, PostgreSQL for database management and PHP programming language to display maps to web pages. The final conclusion of this study found that the geographic information system that was built can show information about the distribution of residents of Cimahi City well so that the government can determine more appropriate policies.

Keywords: Geographic Information System, Population distribution, Cimahi City

\section{Pendahuluan}

Berdasarkan data yang diperoleh dari Badan Pusat Statistik Kota Cimahi, saat ini jumlah penduduk yang mendiami kota Cimahi berjumlah \pm 607.811 jiwa yang tentunya tidak seimbang dengan luas wilayah Kota Cimahi yang hanya $\pm 40 \mathrm{~km}^{2}$. Merujuk pada RPJP Daerah Kota Cimahi 2005-2025 yang menyebutkan bahwa pertumbuhan penduduk dan persebaran nya telah menjadi isu strategis dan perlu diatasi secara bertahap dan berkesinambungan, maka salah satu hal yang bisa dilakukan adalah dengan melakukan monitoring sebaran kependudukan[1]. 
SIG (Sistem informasi geografis) adalah sebuah sistem yang didesain untuk menangkap, menyimpan, memanipulasi, menganalisa, mengatur, dan menampilkan seluruh jenis data geografi [2]. Sistem informasi geografis atau SIG membutuhkan dua tipe data, yaitu data non-spatial dan data spatial. Data spasial merupakan data hasil digitasi peta, pada penelitian ini untuk membuat peta digunakan QGIS yang kemudian dikonversi kedalam PostgreSQL sehingga menghasilkan tipe data Geometry[3].

Selanjutnya untuk mengkonversi data spasial tersebut ke dalam PostgreSQL dibutuhkan ekstensi PostGIS. PostGIS adalah sebuah database spasial berbasis open source sebagai ekstensi dari PostgreSQL yang biasa digunakan untuk memasukkan data spasial ke dalam PostgreSQL[4].

Software QGIS dipilih karena memiliki Bahasa pemrograman yang dapat memungkinkan membuka berbagai macam data spasial dari sumber manapun. Hal ini tentu saja dapat menghemat waktu kita dalam melakukan konversi jenis data. Sifat QGIS yg opensource juga membuatnya menjadi kekuatan utama QGIS. Seluruh tools dan plugin QGIS pun dapat digunakan secara gratis. selain itu, tampilan QGIS yang simple dan user friendly juga merupakan salah satu kelebihannya terlebih bagi para pengguna yg masih baru. Penelitian ini membahas mengenai implementasi Sistem Informasi Geografis untuk memetakan sebaran jumlah penduduk di Kota Cimahi.

\section{Kajian Pustaka}

\subsection{Sistem Informasi Geografis}

Sistem informasi Geografis (SIG) saat ini merupakan perangkat bantu dalam pemetaan serta manajemen informasi berbasis geografis. Melalui perangkat ini kita dapat memvisualisasikan keadaan nyata bumi (real-world) menjadi suatu gambar, Perangkat ini juga membantu kita memahami konsep-konsep fenomena alam terkait aspek geografis maupun keruangan sehingga memudahkan kita mengambil keputusankeputusan perencanaan maupun pengelolaan sesuai dengan kebutuhan[5].

Sistem Informasi Geografis (SIG) adalah seperangkat alat yang mengintegrasikan sumber daya manusia, data geografis, sumber daya teknologi, dan prosedur untuk organisasi, integrasi, penyimpanan, manipulasi, analisis, dan publikasi informasi yang digunakan sebagai input untuk pengambilan keputusan, independen dari bidang aplikasi yang GIS diberikan dibangun[6].

\subsection{PostgreSQL dan PostGIS}

Arsitektur PostgreSQL-PostGIS menjadi arsitektur standar hampir de-facto untuk proyek berbasis FOSS. Peluang untuk mengelola cakupan raster secara efektif di sisi server tidak ada, sementara itu sudah tersedia di pesaing sumber tertutup utama, Oracle Spatial. [7].

\subsection{Penelitian sebelumnya}

Masalah terkait pemetaan sebaran penduduk telah dilakukan dalam beberapa penelitian. Penelitian tentang pemanfaatan SIG untuk pemetaan jumlah penduduk telah dilakukan oleh Ural, dkk pada tahun 2011, hanya saja dikarenakan peta yang digunakan adalah hasil dari citra satelit maka penyajian data dalam bentuk peta terlihat kurang optimal[8].

Selanjutnya Setyorini, pada tahun 2012 telah melakukan analisis terhadap kepadatan penduduk serta proyeksi kebutuhan pemukiman di Kecamatan Depok Sleman pada tahun 
2010-2015, namun penyajian data sebaran masih diproses secara manual dan ditampilkan dalam bentuk tabel dan grafik[9].

Penelitian Budi Santosa dkk, membahas mengenai pemetaan sebaran penduduk berdasarkan tingkatan usia menggunakan software ArcView GIS 3.3 untuk mengembangkan peta dan basis datanya sedangkan untuk menampilkan peta dihalaman web digunakan mapserver 4.4. Sistem ini akan memudahkan instansi terkait untuk mengetahui potensi penduduk (usia produktif atau non-produktif) dari suatu daerah dengan menyediakan informasi bagi para pengambil kebijakan tingkat Propinsi dan Kabupaten untuk menghasilkan perencanaan yang lebih baik dalam pemanfaatan potensi suatui daerah dalam kaitannya dengan pengembangan wilayah yaitu dengan memperhatikan faktorfaktor seperti iklim, kesuburan tanah, tata air, keadaan ekonomi serta kultur penduduk (mata pencahariannya) [10].

Penelitian Yuni Rahayu dkk, bertujuan untuk membangun sistem informasi geografis berbasis web yang menampilkan pemetaan penyebaran dan prediksi jumlah penduduk berdasarkan metode geometrik di wilayah Bandar Lampung. Sistem ini dapat digunakan untuk memudahkan proses pengamatan penyebaran dan prediksi jumlah Penduduk di wilayah Bandar Lampung menggunakan model pertumbuhan geometric[11]. Penelitian oleh Ana Kurniawati dkk, fokus kepada Sistem informasi geografis pemetaan penyebaran penduduk di Kota Bekasi dengan menggunakan Google Maps API, dan Fusion Table serta melakukan uji coba berdasarkan metode blackbox [12].

\section{Metode Penelitian}

Metode RUP (Rational Unified Process) adalah metode pengembangan yang berorientasi pada proses. Gambar 1 menunjukkan secara keseluruhan arsitektur yang dimiliki RUP.

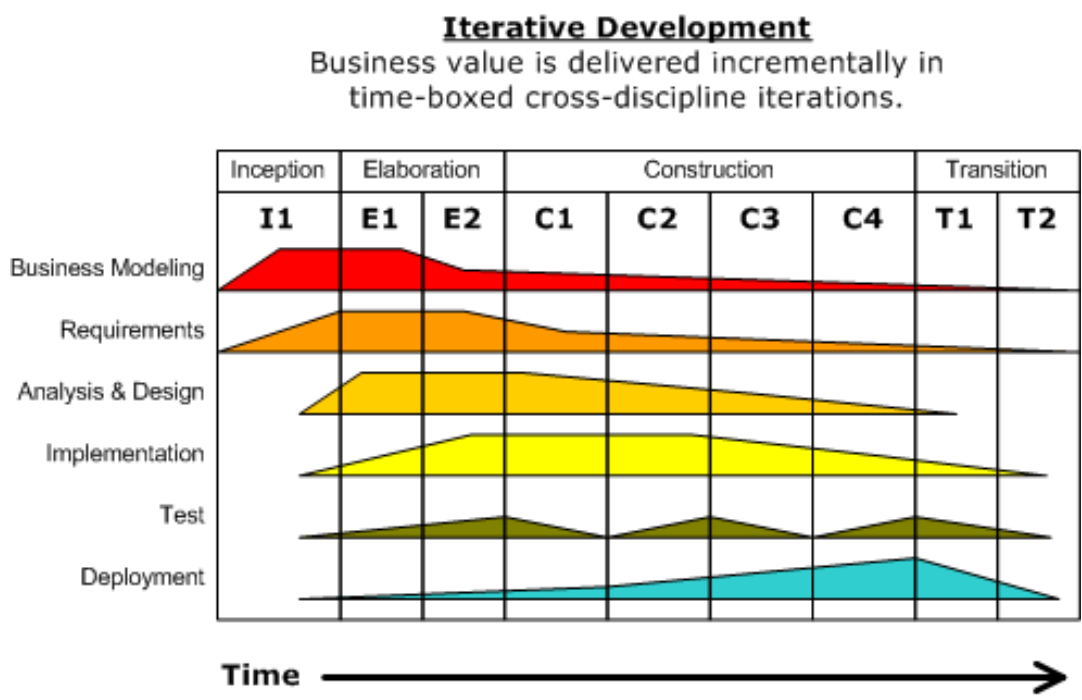

Gambar 1. Arsitektur Rational Unified Process [13].

Terdapat empat tahap pengembangan perangkat lunak dalam metode RUP, yaitu:

\subsection{Inception}

Pada tahap ini pengembang mendefinisikan batasan kegiatan, melakukan analisis kebutuhan user, dan melakukan perancangan awal perangkat lunak (perancangan arsitektural dan use case). 


\subsection{Elaboration}

Pada tahap ini dilakukan perancangan perangkat lunak mulai dari menspesifikasikan fitur perangkat lunak hingga perilisan prototipe versi Betha dari perangkat lunak.

\subsection{Construction}

Pengimplementasian rancangan perangkat lunak yang telah dibuat dilakukan pada tahap ini. Pada akhir tahap ini, perangkat lunak versi akhir yang sudah disetujui oleh user dirilis beserta dokumentasi perangkat lunak.

\subsection{Transition}

Instalasi, deployment dan sosialisasi perangkat lunak dilakukan pada tahap ini.

\section{Hasil dan Pembahasan}

Data wilayah kecamatan, kelurahan yang sudah diinput ke dalam database PostgreSQL masih memerlukan konfigurasi dari layer-layer yang ingin ditampilkan agar peta dapat terlihat pada browser. Proses konfigurasi ini dilakukan dengan menggunakan tools geoserver. Geoserver merupakan jenis software server yang lengkap dan dapat mempublikasikan data ke dalam aplikasi map[14].

\subsection{Fase Inception}

Pada tahap ini kebutuhan dari sistem informasi geografis sebaran jumlah penduduk didefinisikan. Dalam penelitian ini penulis menggunakan permodelan use case. Use Case merupakan urutan langkah-langkah yang secara tindakan saling terkait (scenario), baik terotomatisasi maupun secara manual, untuk tujuan melengkapi satu tugas bisnis tunggal. Pada gambar 2, terlihat bahwa sistem informasi geografis pemetaan sebaran jumlah penduduk di Kota Cimahi memiliki 3 buah use case, yaitu use case manajemen data peta, use case mengakses analisa peta, dan use case login.

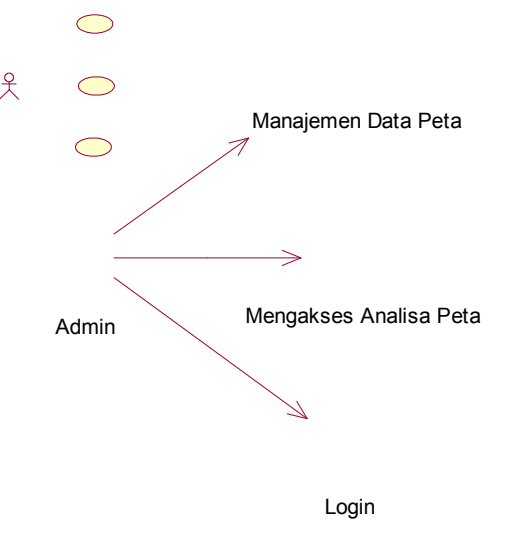

Gambar 2 Use Case Diagram

\subsection{Fase Elaboration}

Selanjutnya pada tahap ini perancangan logika prosedural pada sistem yang akan dibangun dibuat menggunakan activity diagram. Berikut gambar rancangan logika procedural dari sistem informasi geografis pemetaan sebaran jumlah penduduk di Kota Cimahi yang dapat dilihat pada gambar 3, gambar 4, dan gambar 5. 


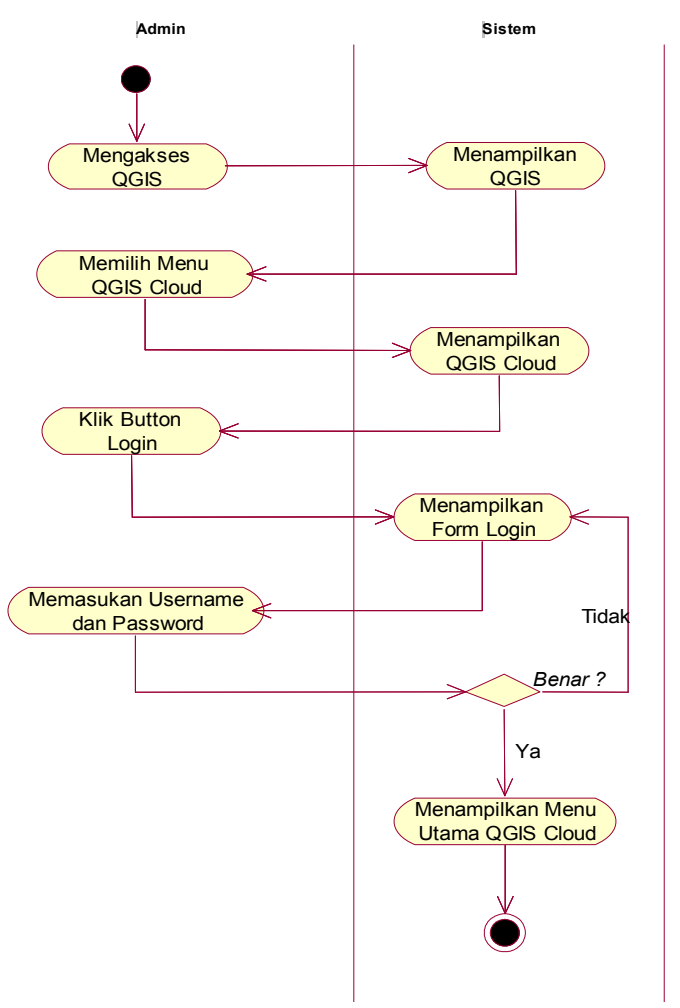

Gambar 3 Activity Diagram Login

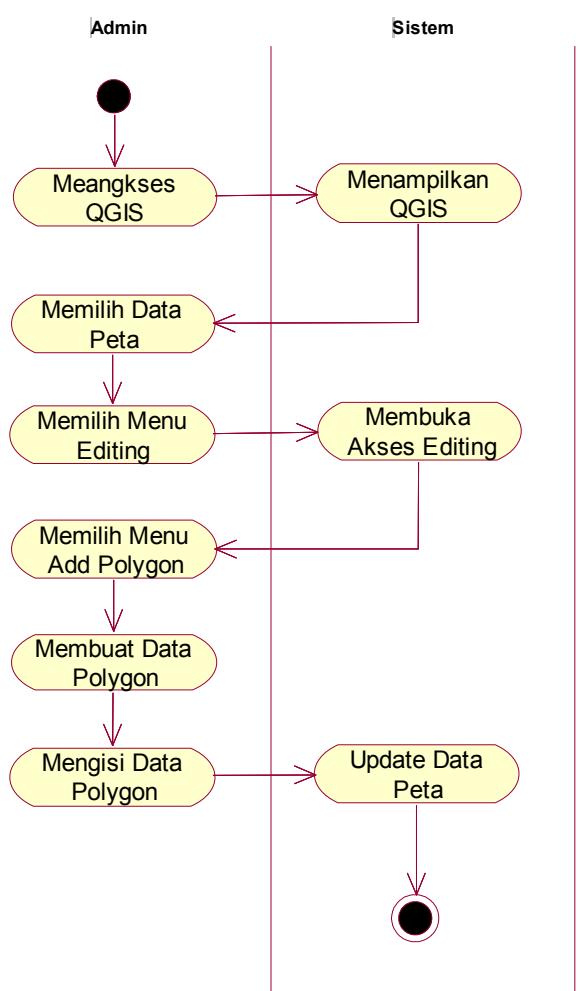

Gambar 4 Activity Diagram Menambah Data Peta 


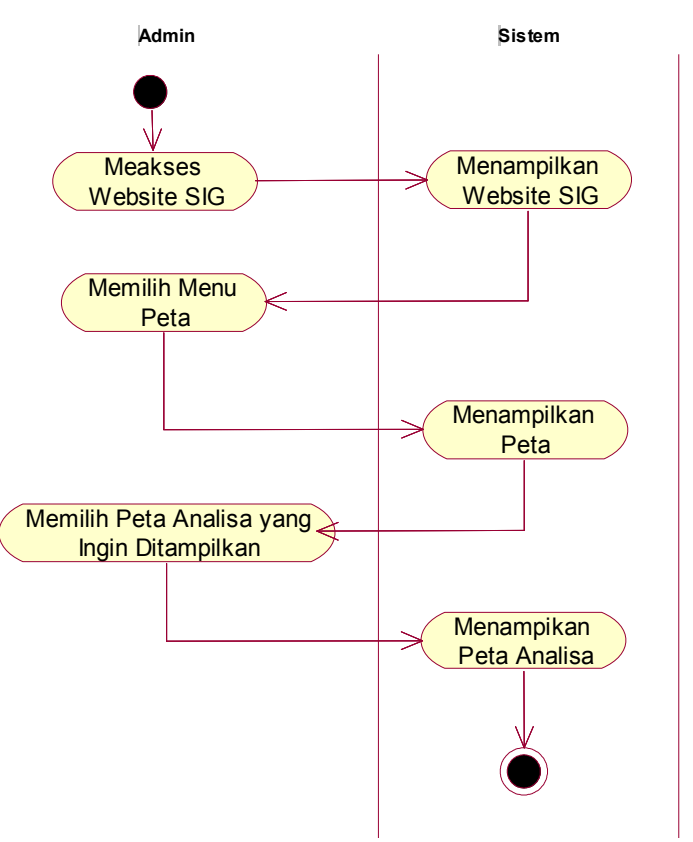

Gambar 5 Activity Diagram Mengakses Analisis Peta

\subsection{Fase Constructions}

Berikut ini adalah beberapa tampilan/interface dari QGIS sebaran data penduduk di Kota Cimahi seperti terlihat pada gambar 6-10.

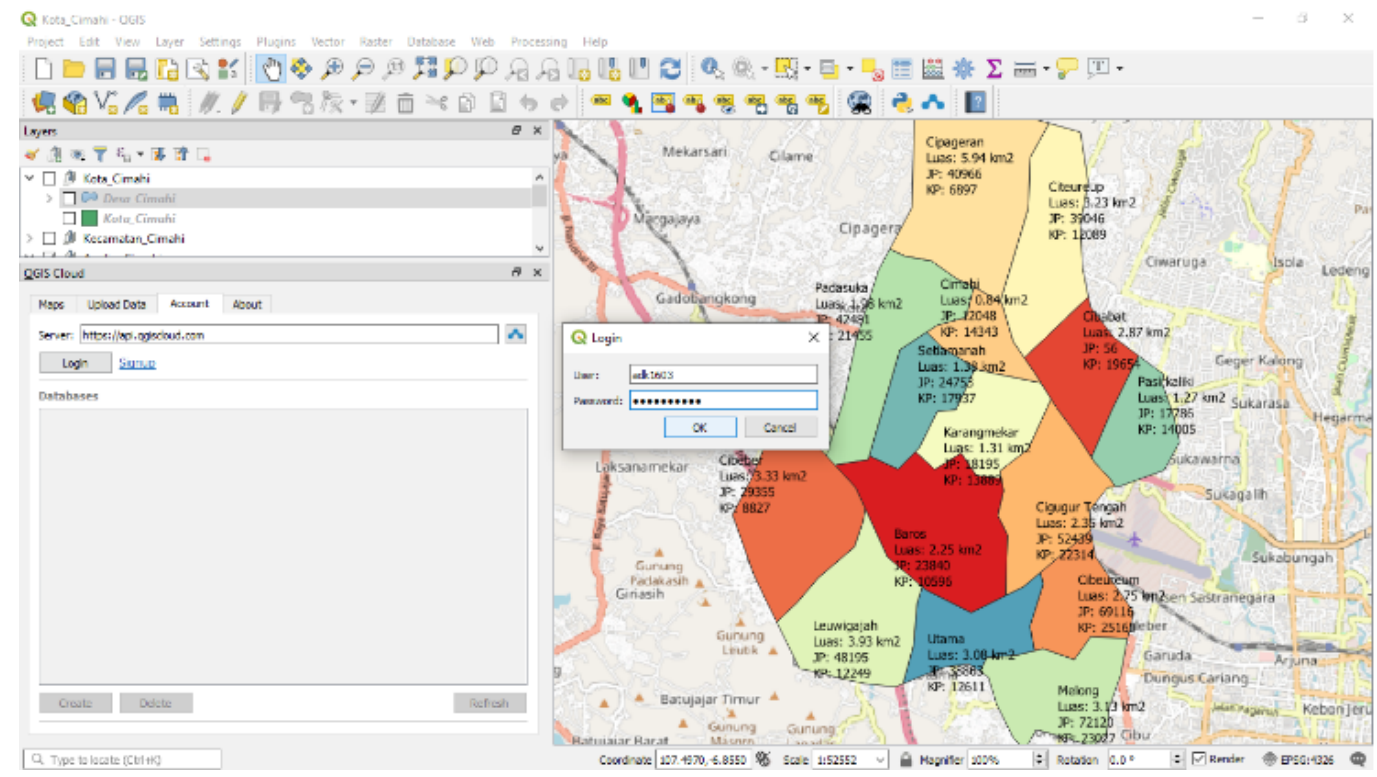

Gambar 6 Login QGIS 


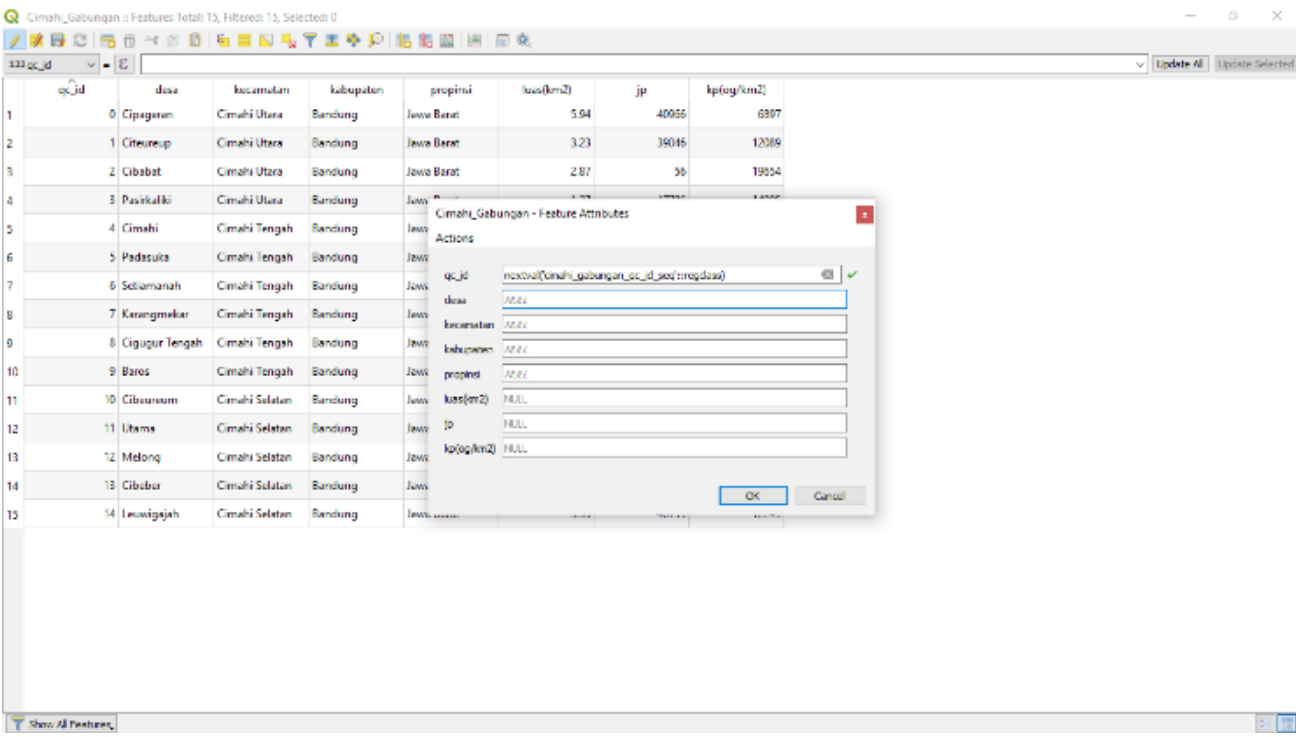

Gambar 7 Tambah Data

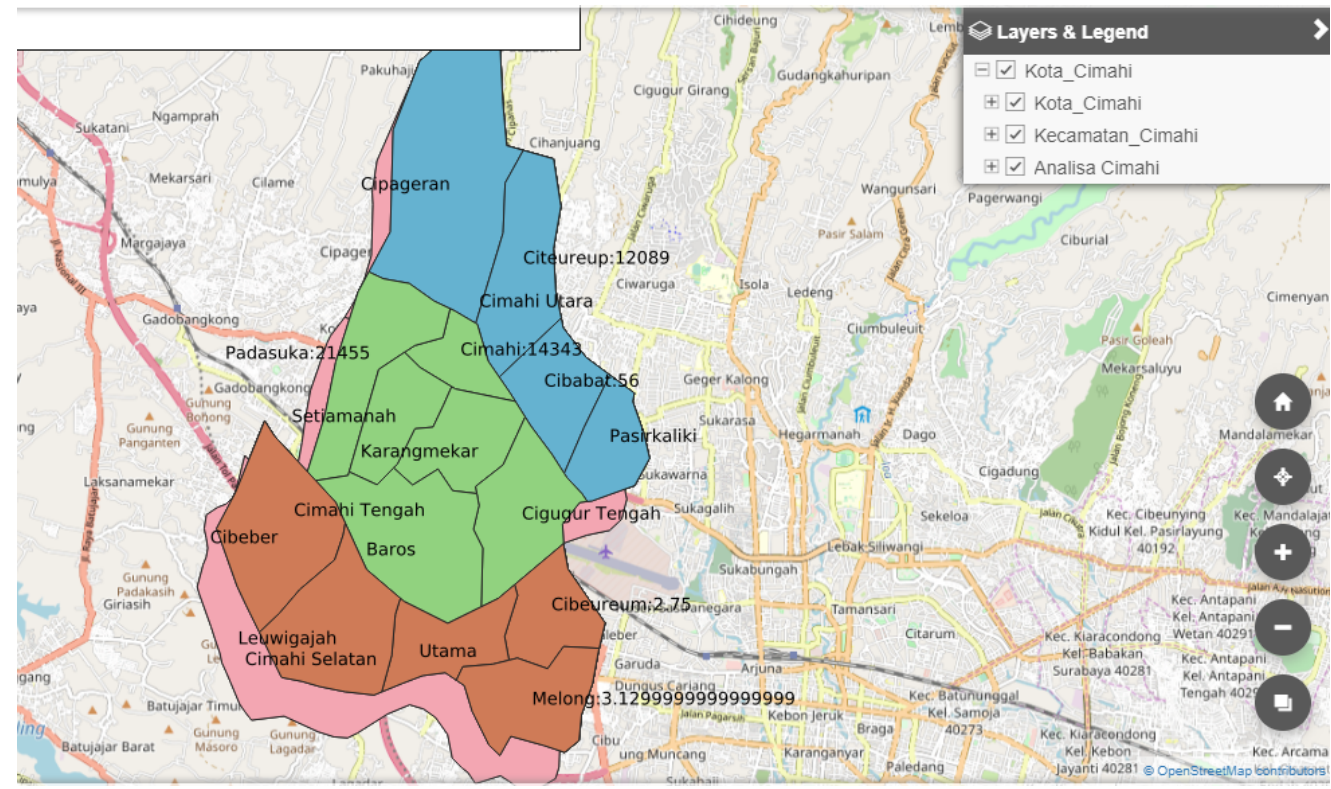

Gambar 8 Peta Dasar Kota Cimahi 


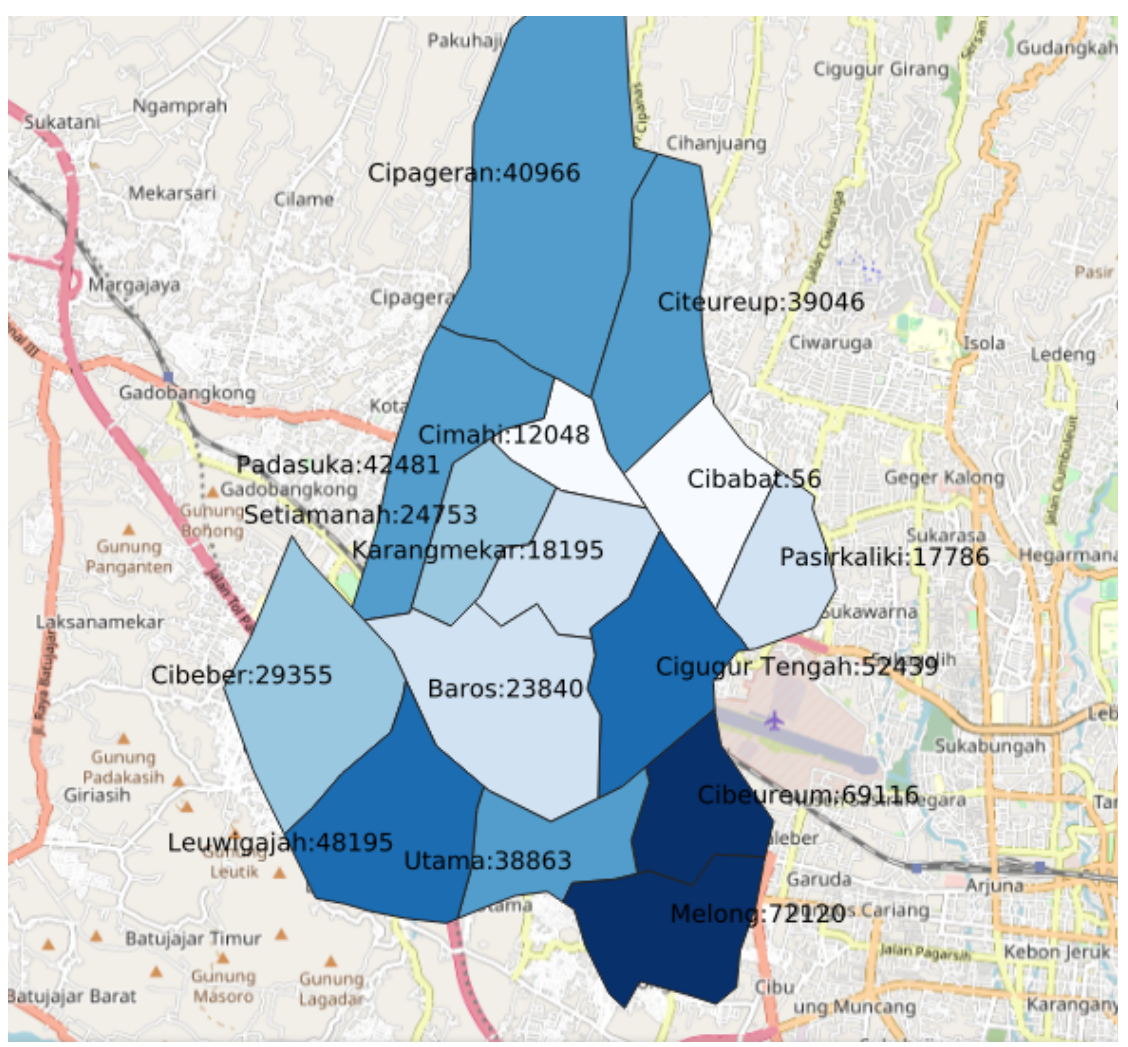

Gambar 9 Peta Sebaran Jumlah Penduduk Kota Cimahi

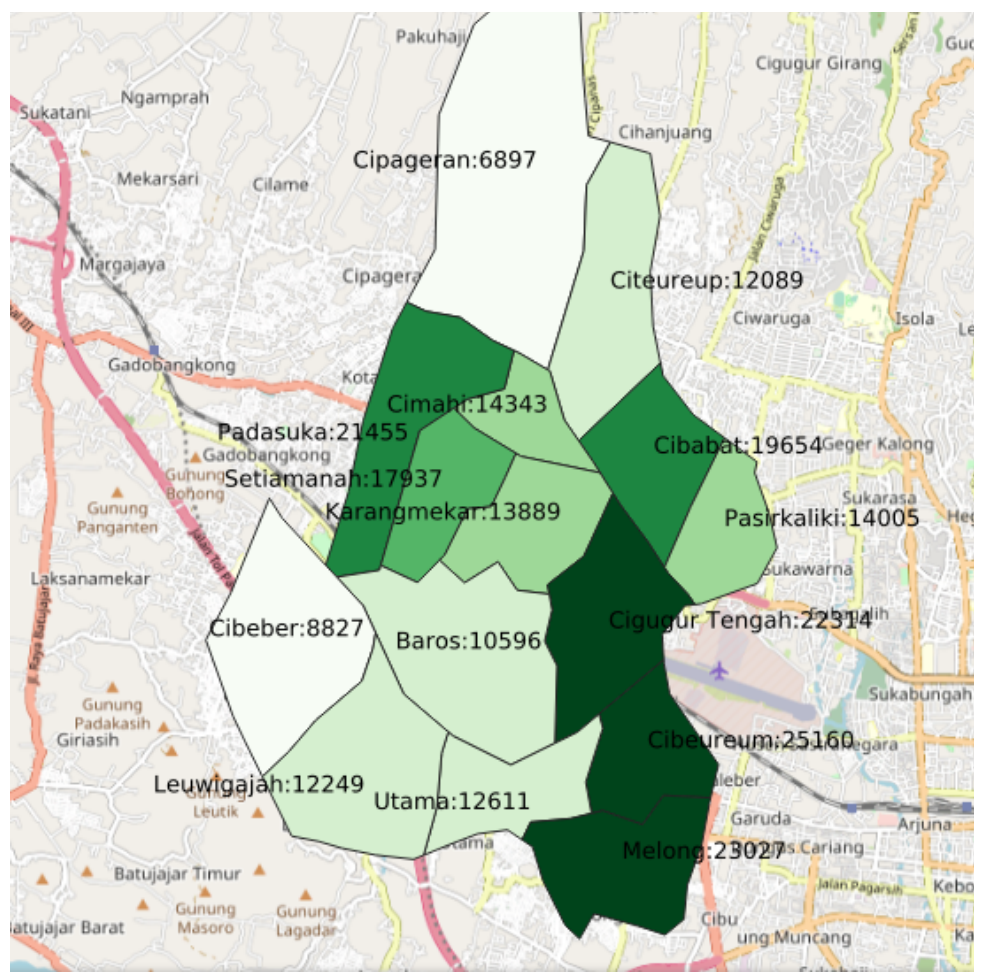

Gambar 10 Peta Kepadatan Penduduk Kota Cimahi

Selanjutnya pada tahap ini juga telah dilakukan pengujian prototype tahap awal, dan hasilnya bisa dilihat pada tabel 1 . 
Tabel 1 Hasil Pengujian

\begin{tabular}{|l|l|l|l|l|}
\hline No & Usecase & Skenario & Hasil yang diharapkan & $\begin{array}{l}\text { Keteranga } \\
\mathrm{n}\end{array}$ \\
\hline 1 & Login & $\begin{array}{l}\text { Input username dan } \\
\text { password kemudian pilih } \\
\text { tombol "login" }\end{array}$ & $\begin{array}{l}\text { Login valid dan dapat } \\
\text { masuk ke menu utama }\end{array}$ & Sesuai \\
\hline 2 & $\begin{array}{l}\text { Manajemen } \\
\text { Data Peta }\end{array}$ & $\begin{array}{l}\text { 1. Tambah data peta } \\
\text { 2. Ubah data peta } \\
\text { 3. Hapus data peta }\end{array}$ & $\begin{array}{l}\text { 1. Form tambah data } \\
\text { berhasil menambah } \\
\text { data pada database } \\
\text { 2. Form ubah data } \\
\text { berhasil mengubah } \\
\text { data pada database } \\
\text { Form hapus data } \\
\text { berhasil menghapus } \\
\text { data pada database } \\
\text { yang sebelumnya juga } \\
\text { ada fungsi alert }\end{array}$ & \\
& Mengakses & Memilih informasi peta & $\begin{array}{l}\text { Menampilkan detail } \\
\text { informasi dari peta yang } \\
\text { dipilih Sesuai }\end{array}$ & \\
\hline 3 & analisa & & \\
\hline
\end{tabular}

\subsection{Fase Transition}

Tahap ini lebih pada deployment atau instalasi sistem agar dapat dimengerti oleh user. Saat ini penelitian baru sampai tahap instalasi sistem dan belum sampai ke dalam tahap sosialisasi.

\section{Kesimpulan}

Kesimpulan akhir yang didapatkan berdasarkan hasil penelitian ini adalah bahwa sistem informasi geografis yang dibuat sudah sesuai dengan analisis dan perancangan yang telah dilakukan sebelumnya. Selanjutnya dalam proses pengujian melalui metode blackbox testing dapat menunjukkan bahwa sistem informasi geografis sebaran jumlah penduduk telah sesuai dengan baik berdasarkan fungsionalitasnya. Hasil penelitian yang berupa informasi sebaran penduduk saja akan lebih baik jika dilengkapi dengan tindak lanjut dari informasi sebaran penduduk yang didapatkan. Oleh karena itu untuk penelitian selanjutnya agar bisa melanjutkan untuk pembuatan prediksi jumlah penduduk di masa yang akan datang menggunakan model prediksi yang telah ada, seperti model aritmatika, model geometrik, maupun regresi linear.

\section{Daftar Pustaka}

[1] “Rencana Pembangunan Jangka Panjang Daerah Kota Cimahi Tahun 2005 - 2025,”. Available: https://cimahikota.go.id/page/detail/78. [Accessed: 15-November-2018]

[2] E. Irwansyah, Sistem Informasi Geografis:Prinsip Dasar dan Pengembangan Aplikasi, DigiBook, 2013

[1] R. Obe, and L. S. Hsu, PostgreSQL: Up and Running, California: O'Reilly Media,2012

[2] R. Obe, and L. S. Hsu, PostGis In Action, California: O'Reilly Media,2011 
[3] E. Prahasta, Konsep-konsep Dasar Sistem Informasi Geografis, Informatika, Bandung, 2002

[4] N. Espinosa, J. Monsalve, and S. Gómez, Análisis de la metodología de los sistemas de información geográfica (SIG) en la cartografía de la guerra en Colombia Tabula Rasa 19 315-353, 2013

[5] E. Agosto, "Vector-raster server-side analysis: a PostGIS benchmark", Applied Geomatic Volume 5 issue 2, 2013

[6] S. Ural, E. Hussain, and J. Shan, Building population mapping with aerial imagery and GIS data, International Journal of Applied Earth Observation and Geoinformation, 13 (6), 841-852, 2011

[7] B. Setyorini, Analisis Kebutuhan Peduduk dan Proyeksi Kebutuhan Pemukiman Kecamatan Depok Sleman tahun 2010-2015. Skripsi, Universitas Muhammadiyah Surakarta, Fakultas Geografi, 2015

[8] B. Santosa, H. Sofyan, and W.A. Widiyastuti, Sistem Informasi Geografis Penyebaran Penduduk Berdasarkan Tingkat Usia Di Kabupaten Sleman Berbasis Web, Seminar Nasional Informatika 2008, UPN "Veteran" Yogyakarta, 2008

[9] Y. Rahayu, K. Muludi, and P. Hijriani, Pemetaan Penyebaran dan Prediksi Jumlah Penduduk Menggunakan Model Geometrik di Wilayah Bandar Lampung Berbasis Web-GIS, Journal of Information Systems Engineering and Business Intelligence, 2016

[10] A. Kurniawati, D. Agusten, S.A. Andrini, Rancang Bangun Sistem Informasi Geografis Pemetaan Penyebaran Penduduk Wilayah Kota Bekasi. Konferensi Nasional Sistem Informasi 2018, STMIK Atma Luhur Pangkalpinang, 2018

[11] The Unified Software Development Process: Classification of Iterations. Retrieved from http://www.idi.ntnu.no/emner/tdt4140/dokumenter/2009/unfied\%20process.ppt.

[12] S. Lacovella, GeoServer Cookbook. United Kingdom. Birmingham: B3 2P B., 2014 